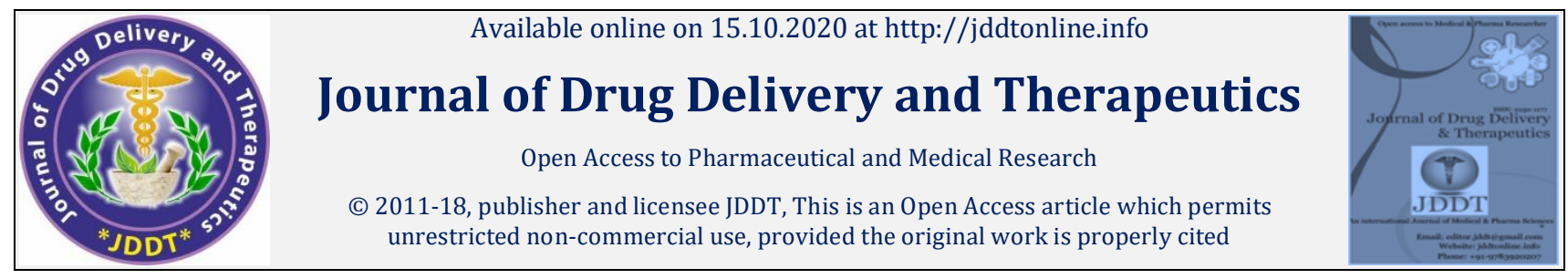

Open Access

Review Article

\title{
Anti-Inflammatory and Anti-Microbial Potential of Plumbago zeylanica L.: A Review
}

\section{Aleem Mohd*}

PG Scholar, Department of pharmacology, National Institute of Unani medicine, Kottigepalya Magadi main road, Bangalore, Karnataka (India). Pin code: 560091

\begin{abstract}
Plumbago zeylanica $\mathrm{L}$. (Pz) is one of the most important medicinal plant belonging to the family Plumbaginaceae. It is a perennial shrub, growing throughout India and most places of Sri Lanka. It contains various bioactive compounds like alkaloids, flavonoids, naphthoquinones, glycoside, saponins, steroids, tri-terpenoids, coumarins, phenolic compounds etc. Of all the chemical constituents, plumbagin is the principal active compound. Plumbagin (5-hydroxy-2-methyl-1, 4-naphthoquinone-C11H803) is primarily present in roots in higher amounts with only about $1 \%$ in the whole plant. The literature reveals that the root and root bark have a wider claim in traditional medicines against various diseases as a memory enhancer, anti-inflammatory, anti-microbial, wound healing, anti-malarial, anti-infertility, anticancer, blood coagulation, and anti-oxidant activities. The present study aims to evaluate the anti-inflammatory and antimicrobial properties of this plant.
\end{abstract}

Keyword: Plumbago zeylanica; Sheetraj; Chitrak; Anti-inflammatory; Antimicrobial; Traditional uses

Article Info: Received 12 Aug 2020; Review Completed 11 Sep 2020; Accepted 24 Sep 2020; Available online 15 Oct 2020

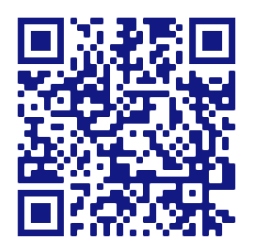

\section{Cite this article as:}

Aleem M, Anti-Inflammatory and Anti-Microbial Potential of Plumbago zeylanica L.: A Review, Journal of Drug Delivery and Therapeutics. 2020; 10(5-s):229-235 http://dx.doi.org/10.22270/jddt.v10i5-s.4445

*Address for Correspondence:

Aleem Mohd, PG Scholar, Department of pharmacology, National Institute of Unani medicine, Kottigepalya Magadi main road, Bangalore, Karnataka (India). Pin code: 560091

\section{INTRODUCTION}

Inflammatory processes play a key role in the body's initial protection following infection or tissue injury, thereby minimising more harm to the affected place. While inflammation reaction plays an important role in biological defence mechanisms in the early stages of infection. Chronic inflammation has long been associated with a wide variety of non-infectious diseases, including arthritis ${ }^{1}$. Steroids play an important role in inflammatory disease management, but due to their toxicity, they should only be used for brief periods or in extremely severe situations where the risks are appropriate. Prolonged use of NSAIDs often involves severe side effects, especially gastrointestinal haemorrhage 2 . After the "golden age" revolution, when almost all classes of essential antibiotics (tetracyclines, cephalosporins, aminoglycosides and macrolides) were discovered and the key problems of chemotherapy were resolved in the 1960s, history nowadays is repeating itself and these exciting compounds are in danger of losing their effectiveness due to the rise in microbial resistance. Its impact on treatment failures associated with multidrug-resistant bacteria is currently substantial and has become a global concern for public health ${ }^{3}$.
As a result, the use of medicinal plants for the treatment and management of diseases like inflammatory and bacterial infections that have existed since time immemorial is becoming increasingly widespread globally 1 .

$\mathrm{Pz}$ is one of the most important medicinal plant, commonly known as Chitraka/Chitramol in Sanskrit, White Leadwort/Ceylon leadwort/Doctorbush in English, Sheetraj Hindi in Urdu, belonging to the family Plumbaginaceae 4,5 . It is widely used in traditional medicine for an antiinflammatory and antimicrobial agent. It is a perennial shrub, growing most places of Sri Lanka and throughout India. In India, especially in Uttar Pradesh, Andhra Pradesh, Karnataka, Kerala and Bengal 6 . In north-east India, it is widely distributed in the wilds of Assam and Meghalaya ${ }^{7}$. In the Arabian Peninsula, it is naturally distributed over Yemen, Oman and the Southwestern region of Saudi Arabia 8. Moreover, it can be found in subtropical and tropical regions above $2 \mathrm{~km}$ from sea level, where soils are rich in trace elements. It grows in lead polluted areas. The Plumbago genus name originated from Latin words plumbum (lead) is believed to refer to lead-blue flower colour or the ability of the sap to create lead-coloured stains on skin, or the belief that the plant was a cure for lead poisoning ${ }^{9}$. In Nigerian 
traditional medicine the root, stem bark and leaves are used as medicinal herbs for a variety of treatments ${ }^{4}$ but in Indian traditional medicine dried mature root is mostly used for medicinal purpose. It contains various chemical constituent like alkaloids, flavonoids, naphthoquinones, glycoside, saponins, steroids, tri-terpenoids, coumarins and phenolic compounds 10 . Many studies showed that plumbagin can be used in combination with existing anticancer drugs, which help to treat chemotherapy-resistant patients 11 . The literature reveals that the root and root bark have wider application in the traditional system of medicines against various diseases as an anti-inflammatory, antimicrobial etc 5 .

\section{MATERIAL AND METHODS}

The literature of $\mathrm{Pz}$ was obtained from online databases including Pub Med, Google Scholar, Scopus, Web of Science and Science Direct. A library search was also conducted from classical Textbooks, PhD Theses, and published Books. The keywords used for the search were Plumbago zeylanica, Shetraj, Ceylon Lead Wort, Chitrak, Doctorbush. Scientific name and synonyms were validated through the Plant list (www.theplantlist.org).

\section{VERNACULAR NAME}

Arabic: Sheetraj, Shitraj; English: Lead Wor, Ceylon Lead Wort, White Flowered Lead Wort, White Lead Wort; Persian: Shitrak, Shitrah; Sanskrit: Agnimata, Chitraka; Ayurveda: Chitraka, Agni, Vahni, Jvalanaakhya, Krshaanu, Hutaasha, Dahana, Sikhi; Unani: labediyoon, Sheetraj Hindi $12-14$

\section{BOTANY}

The family Plumbaginaceae consists of 10 genera and 280 species. There are three species in the genus Plumbago, namely Plumbago indica L./ P. Rosea L., P. capensis L., and P. zeylanica L., which are spread across India. In India, Pz grows as a wild species in various parts but is also cultivated because of its large therapeutic applications 12,15. There is no consensus in the literature citing $\mathrm{Pz}$ as being listed as herb or shrub. Its roots are $30 \mathrm{~cm}$ or more in length, $6 \mathrm{~mm}$ or more in diameter, slightly branched with very fewer secondary roots, having a smooth and unbroken texture, light yellow colour when fresh and reddish to pale brown when dry. Dried roots are uniform, cylindrical in shape, smooth surface and woody hard with very strong having a bitter taste and a distinct odour with acrid 16 . Stems are somewhat woody, spreading, terete, striate, globous. It is around 0.5-2 m (1.6-6.6 ft) tall. The bark is thin and brown ${ }^{17}$. Leaves are dark green and are simple, elliptical with hairy margins along with alternate positioning on the stem with the gap of up to 3 inches and thickness of 1.5 inches. Petioles are thin and with an approximate length of $0.5 \mathrm{~mm}$ and native stipules are present 18 . The inflorescence is about $6-30 \mathrm{~cm}$ long and many-flowered terminal raceme-type. Flowers are Bisexual, white in colour, $10-25 \mathrm{~cm}$ long, with a diameter of $1 / 2$ to $3 / 4$ inch ${ }^{17}$. Flowers are borne in spikes, whereas the rachis of the spike is pubescent or glandular. Flowers also have a tubular calyx (7-11 mm long and 5-ribbed) with glandular trichomes which secrete a sticky mucilage ${ }^{19}$. Corolla is white, very slender, and tubular and stamens are 5, free. Ovary superior, 5 -gonous, one-celled, ovule one basal ${ }^{17}$. The plant flowers round the year and pollination are primarily by insects. The mucilaginous glands aid in trapping insects and fruit dispersal by animals 20 . Fruits are oblong (7.5-8 $\mathrm{mm}$ long) five-furrowed capsule containing a single seed. Each seed is oblong in structure, 5-6 mm long and reddish-brown to dark brown 17 and its capsules are enclosed by persistent viscid calyx 21. Panda et al., 2015 22, examine the patterns and levels of morphological and genetic variability within/among populations and ascertain whether these variations are dependent on geographical conditions; and to evaluate genetic differentiation and population structure within the species.

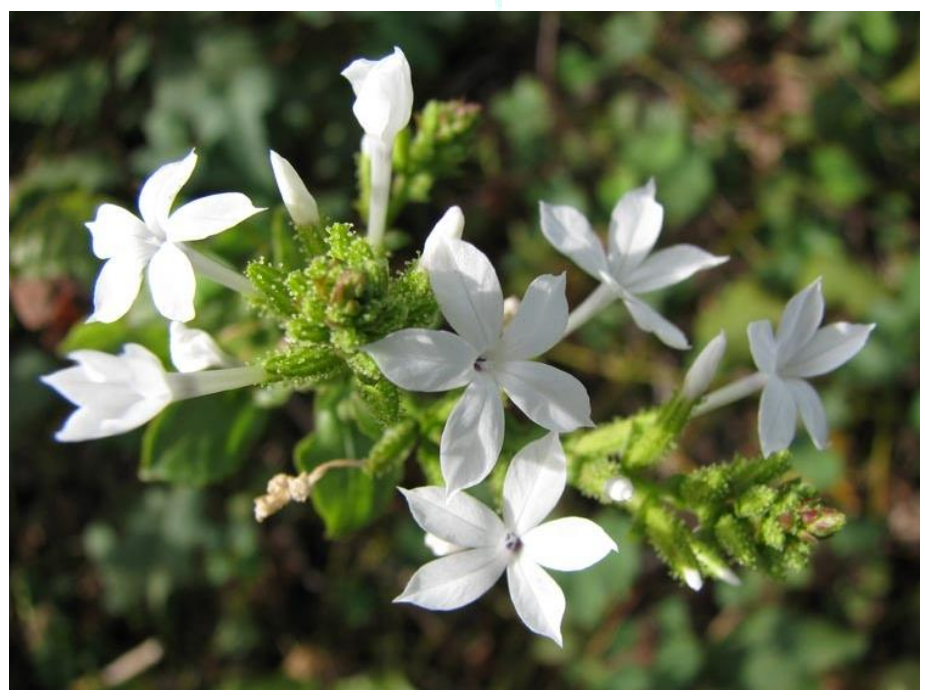

Plumbago zeylanica flower

Source: http://ayurveda.alandiashram.org/ayurvedic-herbs/chitrak-plumbago-zeylanica 


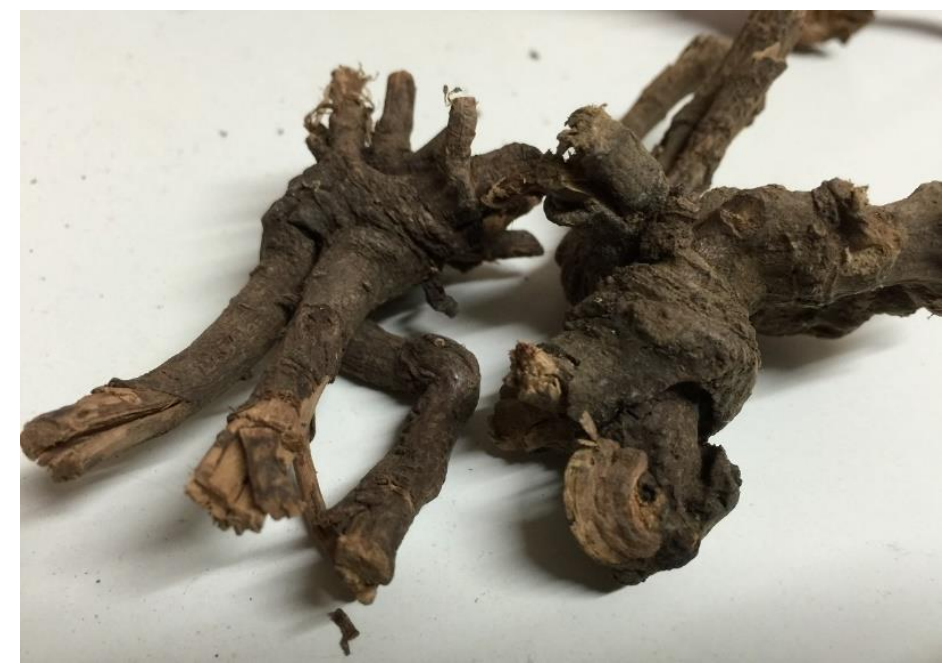

Plumbago zeylanica dried root

Source: https://herbalveda.co.uk/shop/herbs/whole-herbs/chitrak-roots-plumbago-zeylanica/

\section{TRADITIONAL USES}

In the traditional system of medicine, $\mathrm{Pz}$ possesses Abortifacient; Alexeteric; Antipyretic; Antiseptic; Aphrodisiac; Astringent; Carminative; Choleretic; Diaphoretic; Digestive; Diuretic; Expectorant; Laxative; Stimulant and Tonic actions ${ }^{23}$. Its root decoction mixed with roots of Moringa borziana, has been used to treat Gonorrhoea 24. In Iwo, Ibadan and Southwest Nigeria, infusion of $\mathrm{Pz}$ root along with other ingredients are used to treat Lung and breast cancer 25. In Ethiopia root has Crushed, squeezed and applied to skin lesions to treat anthrax while the powdered roots or leaves are used to treat gonorrhoea, syphilis, tuberculosis, rheumatic pain, swellings and wounds 26 . In Nigeria, the roots are used to treat rheumatic swelling, scabies and ulcers ${ }^{4}$. In leprosy and other obstinate skin diseases, root paste prepared with milk or vinegar or salt and water is used externally. Its cold infusion is used to treat influenza and black-water fever Experimentally, plumbagin which is naphthoquinone derivatives, prevent the accumulation of triglycerides in liver and aorta ${ }^{12}$. Intake of $10 \mathrm{gm}$ of roots powder of $\mathrm{Pz}$ with honey ensures quick delivery 27.

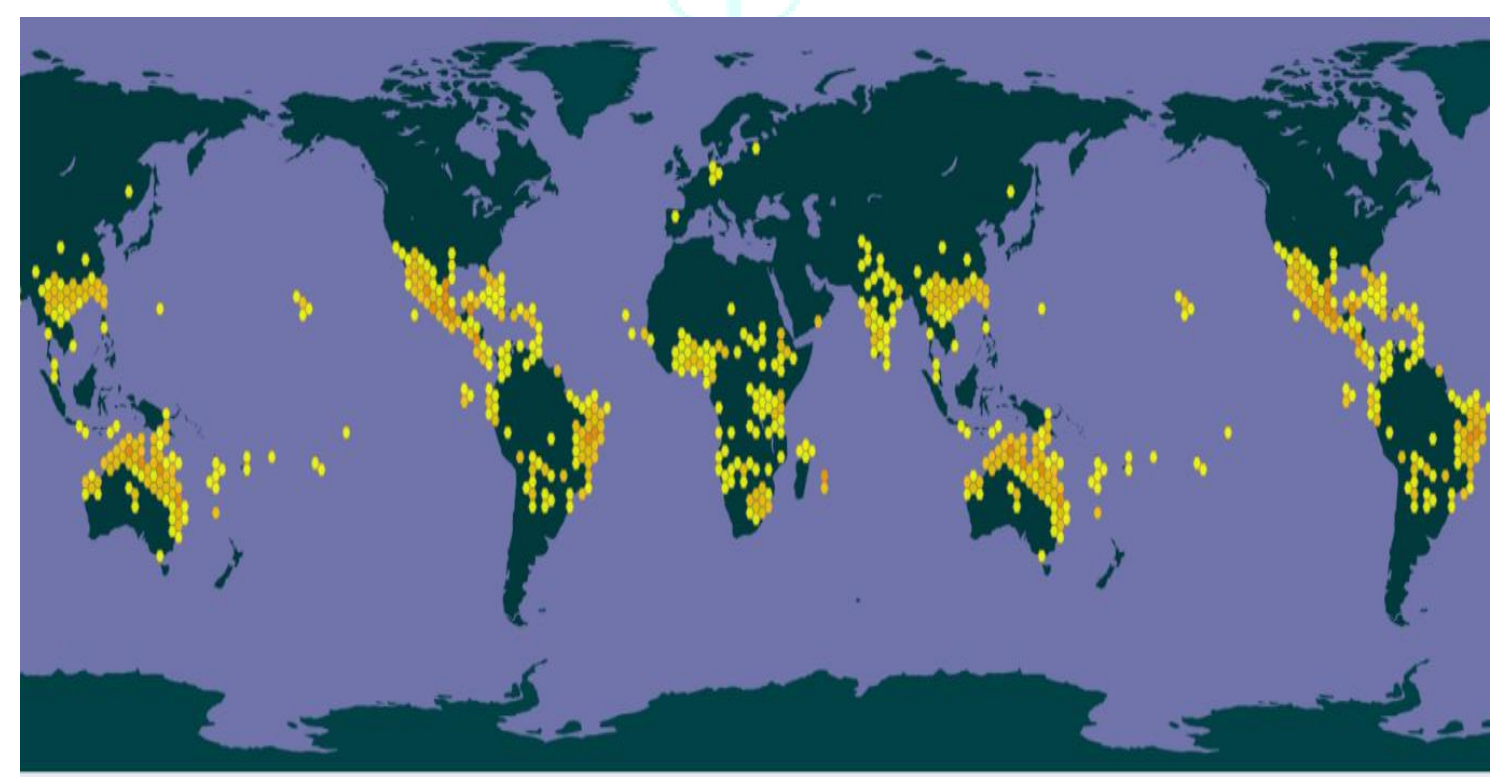

Distribution of Plumbago zeylanica worldwide

Source: https://www.gbif.org/species/3082282

\section{CHEMICAL CONSTITUENT}

$\mathrm{Pz}$ comprises a range of essential chemical compounds. The GC-MS analysis of Pz revealed the presence of 40 compounds that could contribute to the medicinal property of the plant 5 . Different parts of the plant possess alkaloids, carbohydrates, triterpenoids, flavonoids, gums, mucilage, protein, fatty acids, saponin, 8,28 plumbagin, plumbagic acid, chitanone, plumbaginol, dihydroflavinol, campesterol, stigmasterol, ISSN: 2250-1177 sitosterol, glucopyranoside, sitosterol, 29 naphthoquinones, glycosides, steroids, tannins, phenolic compounds and coumarins 15,30 .

Of all the chemical constituents, plumbagin is the principal active compound. Plumbagin (5-hydroxy-2-methyl-1, 4naphthoquinone-C11H803) is primarily present in roots in higher amounts with only about $1 \%$ in the whole plant 15,31 . All parts of the plant are used but roots are considered as the 
most active, prominent and effective herbal drug ${ }^{32}$. Its Roots contains Napthoquinone like 2-hydroxy-1,4-naphthoquinone (lawsone) $\quad 33$ (5,7-dihydroxy-8-methoxy-2-methyl-1,4naphthoquinone (plumbagin), Biplumbagin (Chitranon), Chloroplumbagin, Maritinone, Elliptinone, Lapachol, Plumbic acid, enzymes like invertase and protease along with other compounds such as plumbazeylanone, droserone, isozeylinone, fructose, glucose, zeylinone, Coumarins like 5mrthoxyseselin, seselin, suberosin, xanthyletin, xanthoxyletin, 29 oleic acid (19.95\%), b-asarone (14.08\%), naphtho $(2,3-\beta)$ furan-2(3H)-one $\quad(7.68 \%)$, ethyl pmethoxycinnamate $(4.58 \%)$, and $n$-hexadecanoic acid $(2.18 \%)^{8}$.

\section{PHARMACOLOGICAL ACTIVITY}

$\mathrm{Pz}$ used for centuries to treat a wide variety of diseases has shown great potential as a safe and effective multifunctional medicinal agent 21 . Many parts of the plant are used but there are considerable pharmacological properties in the roots. The powdered bark, root or leaves are used to treat gonorrhoea, syphilis, tuberculosis, rheumatic pain, wound healing, piles, skin diseases, and also reported to have antibacterial, antifungal and cantharides properties 19 . Besides its traditional uses, several recent reports have demonstrated hepatoprotective, immunomodulatory, antitumor anti-inflammatory, anti-diabetic, memory inducing, lipid metabolism, anti-malarial, allergic and modulatory, anti-fertility, anti-bacterial, anti-viral, anticancer, antioxidant and larvicidal activity 10 .<smiles>CC1=CC(=O)c2c(O)cccc2C1=O</smiles>

\section{Chemical structure of Plumbagin}

\subsection{Anti-inflammatory activity}

Plumbago species are one of the most important medicinal plants which are used for anti-inflammatory activity 34 . Oyedapo, 199635 investigated the phosphate-buffered saline extract of the roots of Pz for anti-inflammatory activity. The extract stabilized red blood cells subjected to both heat and hypotonic induced lyses. The extract exhibited a biphasic response and the enzymatic activities of both alkaline and acid phosphatases were reduced. Another study showed that $\mathrm{Pz}$ reduces oedema thus comforting the body part, and suppress the NF-kappa $\beta$ activation in the tumour cells and also prevent graft versus host disease ${ }^{36}$. (Sheeja et al., 2010 37 carried out the anti-inflammatory activities of various leaf extracts of $\mathrm{Pz}$ using in vivo experimental models at two dose levels (200 and $400 \mathrm{mg} / \mathrm{kg}$, p.o.). The acetone extract ( $\mathrm{p}<$ 0.01 ) significantly decreased inflammation in rats induced by carrageenan compared to the control group. Reducing the anti-inflammatory process by extracting petroleum ether, acetone extract, and fractions F2 and F3, obtained during 3-4 $\mathrm{h}$, is possibly linked to a reduction in prostaglandin synthesis and release, rather than preformed inflammatory agents. In another study, the methanolic extracts of the root of $\mathrm{Pz}$ at 300 and $500 \mathrm{mg} / \mathrm{kg}$ produced 31.03 and $60.3 \%$ inhibition of acute inflammation, respectively, in Carrageenin induced raw paw oedema 34 . Another study reported that $\mathrm{Pz}$ reduces oedema significantly compared to aspirin 38 . V. et al., 201439 investigated the Anti-inflammatory activity of hydroalcoholic extract of Pz root bark through in-vitro Human Red Blood Cell Membrane protective activity, and in-vivo through
Carrageenan induced rat paw oedema and Complete Freund's Adjuvant induced chronic inflammatory model in rat. In both acute and chronic model of inflammation hydroalcoholic extract of root bark of Pz showed moderate anti-inflammatory at the dosage of $250 \mathrm{mg} / \mathrm{kg} \mathrm{bw}$ comparable with standard Indomethacin. Carrageenan injection is the biphasic occurrence that contributes to the development of paw oedema in the rat. The first step is due to histamine and serotonin release lasting one hour. The second step is triggered by the release of prostaglandins, lysosomes and proteases. Carrageenan injection in the rat paw induces the release of bradykinin which results in the development of prostaglandins responsible for the formation of inflammatory exudates. The mechanism of antiinflammatory activity of hydroalcoholic extract Pz might be due to prostaglandins inhibition. Nile et al., 2015 40, using diene-conjugate and $\beta$-glucuronidase assays for determination of Anti-inflammatory activity. The root and shoot extracts of $\mathrm{Pz}$ revealed anti-inflammatory activity at a concentration of $25,50,75$, and $100 \mathrm{mg} / \mathrm{mL}$.

Another research conducted to determine the antiinflammatory potential in vivo and in vitro of selected medicinal plants used in traditional Indian medicine. The sequentially extracted plant samples including $\mathrm{Pz}$ in water, ethanol and hexane were evaluated in-vitro for COX-1 and 2 inhibitory and antioxidant activities. The in vivo antiinflammatory activity was assessed using carrageenan and Phorbol Myristate Acetate induced mice oedema. The results reveal that $\mathrm{Pz}$ inhibits COX-2 (mean activity 42.86\%) as compared to COX-1 (mean activity $25.91 \%$ ) 41 . PZE-6, a freeze-dried ethyl acetate fraction, purified from the roots of $\mathrm{Pz}$, was efficacious in preventing joint inflammation when treatment was started before the onset of joint inflammation. PZE-6 also substantially suppressed arthritis by reducing paw volume, clinical score and delayed-type hypersensitivity reaction. Moreover, $20 \mathrm{mg} / \mathrm{Kg}$ of PZE- 6 was found to inhibit the development of inflammation in adjuvant-induced arthritis rats 42 . The dichloromethane extract of $\mathrm{Pz}$ shown a significant $(\mathrm{p}<0.05)$ dose-dependent protection against carrageenan-induced paw oedema. At the first hour, $\mathrm{Pz}$ showed an inhibition effect of oedema in the different doses of $250 \mathrm{mg} / \mathrm{kg}$ and $500 \mathrm{mg} / \mathrm{kg}$ to be 28.57 and $31.79 \%$, respectively. At the third hour, the paw oedema inhibition was found to be 30.70 and $40.15 \%$, respectively. At 500 $\mathrm{mg} / \mathrm{kg} \mathrm{Pz}$ was comparable to diclofenac $(25 \mathrm{mg} / \mathrm{kg})$ in the inhibition of paw oedema. The effect of DMEPZ may be attributed to its free radical scavenger activity and protection of apoptosis 43. In Another study, Plumbagin prominently hampered high mobility group box 1 expression and subsequently quelled inflammatory cascades, as nuclear factor $\kappa \mathrm{B}(\mathrm{NF}-\kappa \mathrm{B})$, tumour necrosis factor-alpha (TNF- $\alpha)$ and myeloperoxidase (MPO) activity ${ }^{44}$.

\subsection{Anti-microbial activity}

The emergence and prevalence of drug-resistant pathogenic microorganisms have led to a decline in the efficacy of traditional antimicrobial therapy. Thus, treatment of infections is increasingly becoming more difficult. To address this emerging issue, novel therapies must be developed to spare existing broad-spectrum antimicrobials including antibiotics. An in vivo study was carried out by Abdul and Ramchender, 1995 45, in this study, the bactericidal capacity of plumbagin-treated mouse macrophages was estimated against Staphylococcus aureus. The result indicates that the macrophage bactericidal activity increases with low concentration plumbagin by potentiating the oxyradical release whereas it has an inhibitory effect at the higher concentration. 
In another study, Pz (root) was prepared in extracts of three different forms, namely hexane, alcoholic and aqueous extracts and tested against Staph. aureus, Bacillus subtilis, E. coli, Pseudomonas aeruginosa, Salmonella typhimurium and Proteus Vulgaris. The result possesses that $\mathrm{Pz}$ produced outstanding antimicrobial effect with inhibition zone greater than $20 \mathrm{~mm}$ and alcoholic extracts exhibited the highest degree of antimicrobial activity as compared to aqueous and hexane extracts fractions ${ }^{46}$.

Lemma et al., 200247 studied the antibacterial activity of polar and non-polar extracts of roots $\mathrm{Pz}$ by using hole plate diffusion method against some pneumonia-causing pathogens. The result showed that the aqueous extract did not exhibit any activity while petroleum ether extract was found to have strong antibacterial effects as compared to the ethanol extract. The synergistic activity of Pz-based antimycobacterial constituents was assessed against four atypical species, namely Mycobacterium intracellulare, M smegmatis, $\mathrm{M}$ xenopei, and $\mathrm{M}$ chelonei, in combination with isonicotinic acid hydrazide (INH). The findings showed that the plumbagin MIC values were reduced from 1.25-2.5 to $0.15-0.3 \mu \mathrm{g} / \mathrm{ml}$ due to collaboration with INH. When tested against the resistant strain of $M$. tuberculosis H37Rv, plumbagin and $7 \beta$-hydroxyabieta-8,13-dien-11,12-dione exhibited inhibitory activity at $<12.5 \mu \mathrm{g} / \mathrm{mL}$, while others were inactive at this concentration ${ }^{48}$. By using agar diffusion and dilution methods the ethanol, ethyl acetate and acetone extracts of $\mathrm{Pz}$ showed higher anti-H. pylori activity except for water extract 49 . Aqil et al., 200650 studied the antimethicillin-resistant Staphylococcus aureus (MRSA) activity of ethanolic extracts of four medicinal plants including $\mathrm{Pz}$ (root). The result shows the ethyl acetate, acetone and methanol fractions of $\mathrm{Pz}$ demonstrated antibacterial activity and inhibition zone size ranged from 11 to $44 \mathrm{~mm}$ and minimum inhibitory concentration (MIC) varied from 0.32 to $3.25 \mathrm{mg} / \mathrm{ml}$. The potency of these fractions based on the zone of inhibition and MIC value was relatively higher in ethyl acetate fraction of Pz. ${ }^{51}$ screened ethanolic extracts of 66 plants against nine different bacteria. The highest activity against all groups of bacteria was found in Pz. Also, these extracts showed synergistic interaction with tetracycline, chloramphenicol and ciprofloxacin against S. aureus and/or E. coli. Six plants, Pz, H. indicus, A. calamus, P. granatum, H. antidysenterica and D. regia, were further subjected to fractionation-based study. Gram-positive and Gram-negative MDR bacteria are almost equally sensitive to these extracts/fractions, indicating their broad-spectrum nature. Ahmad and Aqil, $2007{ }^{46}$ studied in-vitro efficacy of alcoholic crude extracts of 15 medicinal plants against extendedspectrum $\beta$-lactamases (ES $\beta \mathrm{L})$ producing multidrugresistant enteric bacteria. The result showed that $\mathrm{Pz}$ demonstrated relatively high activity as compared to other plant extracts.

In another research, an in vitro antimicrobial activity of plumbagin was done by (Jeyachandran et al., 2009. The result indicates Plumbagin $(20 \mu \mathrm{g} / \mathrm{disc})$ showed good activity against Escherichia coli $(25.6 \pm 0.56 \mathrm{~mm})$, Salmonella typhi $(24.3 \pm 0.23 \mathrm{~mm})$, Staphylococcus aureus $(21.6 \pm 0.55$ $\mathrm{mm})$, Klebsiella pneumoniae $(19.8 \pm 0.76 \mathrm{~mm})$, Serratia marcescens $(17.6 \pm 0.65 \mathrm{~mm})$ and Bacillus subtilis $(14.5 \pm 0.76$ $\mathrm{mm})$. Proteus vulgaris $(10.1 \pm 0.14 \mathrm{~mm})$ and Pseudomonas aeruginosa $(9.6 \pm 0.67 \mathrm{~mm})$ displayed mild aggression against the other species. In this study also Methanol, chloroform and aqueous extracts of $\mathrm{Pz}$ root were tested against various gram-negative and gram-positive bacteria. The result shows that Pz's chloroform root extracts displayed strong activity against Escherichia coli $(16.7 \pm 0.14 \mathrm{~mm})$, Salmonella typhi $(14.3 \pm 0.04 \mathrm{~mm})$, and Staphylococcus aureus $(12.0 \pm 0.54$ $\mathrm{mm})$. The inhibition of Klebsiella pneumoniae $(9.2 \pm 0.73$ $\mathrm{mm})$, Serratia marcescens $(8.6 \pm 0.07 \mathrm{~mm})$, and Bacillus subtilis $(8.0 \pm 0.61 \mathrm{~mm})$ was moderate and poor against Proteus vulgaris $(5.9 \pm 0.55 \mathrm{~mm})$ and Pseudomonas aeruginosa $(4.8 \pm 0.87 \mathrm{~mm}){ }^{52}$. Another study, the different alcoholic solvents of the root of the $\mathrm{Pz}$ were tested against the three human pathogenic bacteria viz., Escherichia coli, Salmonella typhi and Staphylococcus aureus by adapting the disc diffusion method. The results showed that all of the extracts had a varied degree of antimicrobial activity against the pathogens tested. However, the acetone extracts at $100 \%$ concentrations exhibited higher inhibition zone $(27 \mathrm{~mm})$ against the bacteria, Salmonella typhi 53.

Jetty et al., 201054 isolated, separated and evaluated the antimicrobial properties of compounds such as neoisoshinanolone and 1-epineo-isoshinanolone from the roots of $\mathrm{Pz}$. 1-epineo-isoshinanolone is more active with a MIC of 12.5 to $25 \mu \mathrm{g} / \mathrm{ml}$, whereas neoisoshinanolone has recorded a MIC of 50 to $100 \mu \mathrm{g} / \mathrm{ml}$. The activities are compared with plumbagin ( 0.78 to $3.13 \mu / \mathrm{ml}$ ) and standards streptomycin for bacteria and nystatin for fungi. The root extract of $\mathrm{Pz}$ possesses good antimicrobial activity. In another study, methanolic extract of $\mathrm{Pz}$ at 50 and $100 \mathrm{mg} / \mathrm{ml}$ concentrations showed marked inhibitory effect against Bacillus subtilis, Staphylococcus aureus, Escherichia coli and Salmonella typhi with MIC values $0.3125,0.3125,2.5$ and $0.625 \mu \mathrm{g} / \mathrm{ml}$ respectively 55 . In an in vitro study, petroleum ether, chloroform and alcoholic extract of leaves of $\mathrm{Pz}$ were evaluated on microbial strains like gram-positive species Staphylococcus aureus, and Bacillus subtilis and gramnegative species Escherichia coli and Pseudomonas aeruginosa by agar disc diffusion method. The result possesses the alcoholic extract of leaves of $\mathrm{Pz}$ shows maximum antimicrobial activity against all microbial strain 56.

Similarly, Petroleum ether, ethanol and aqueous extract of leaves and stems of Pz investigated against bacteria by paper disc method. The result suggests that the maximum activity was observed in ethanol extract against Micrococcus luteus $(12 \mathrm{~mm})$ and minimum activity was observed in petroleum ether extract against Staphylococcus aureus and Micrococcus luteus at inhibition range was observed $(7 \mathrm{~mm}){ }^{57}$. Another an in-vitro antimicrobial evaluation was carried out by using chloroform, acetone and ethanolic extract of same species of plant $\mathrm{Pz}$ collected from two different Eastern Himalayan regions by agar disc diffusion method and it was performed on gram-negative bacteria Salmonella typhi and Pseudomonas aeruginosa and gram-positive bacteria Bacillus subtilis and Staphylococcus aureus. The result possesses that the ethanolic extracts of both region plants showed significant antibacterial activity against all the organisms, while chloroform and acetone fractions showed moderate activity 58. Patwardhan et al., 201559 studies showed that the root extracts cured plasmid-encoded antibiotic resistances from the clinical isolates and reference strains at curing efficiencies of 4 to $100 \%$. Petroleum ether root extract of $\mathrm{Pz}$ demonstrated higher plasmid curing activity than the known plasmid curing agents like ethidium bromide or acridine orange. A study carried out by (Shweta and Dubey, 2015 60, In this study aqueous, methanol extract, and acetone extract of $\mathrm{Pz}$ leaves were tested against various bacteria (gram +Ve, \& gram -Ve bacteria) and fungus. The result shows that the aqueous extract of $\mathrm{Pz}$ is more effective in all micro-organism as compared to methanol extract and acetone extract. Antimicrobial evaluation of crude extract of $\mathrm{Pz}$ against S. aureus ATCC, MRSA, S. pneumoniae ATCC, S. pneumoniae (clinical) (gram positive bacteria), $\mathrm{K}$. pneumoniae (clinical), S. boydii ATCC, E. coli ATCC, E. coli 
(clinical) (gram negative bacteria) and C. albicans (clinical) (fungus) were showing a higher antimicrobial activity 61 .

A study carried out to screen the antibacterial potentials of plant extract $\mathrm{Pz}$ extract was prepared in methanol, hexane and chloroform by Soxhlet extractor and tested for its antibacterial activity against clinical pathogens i.e. Enterococcus, E. coli, Klebsiella pneumonia, Lactobacillus acidophilus and Staphylococcus aureus by well diffusion method. Results revealed that plant extracts possess potential antibacterial activity against the tested organism but methanol extract showed more inhibitory effect than the other plant extracts 62. Another study carried out to determine the antimicrobial activities of methanolic extracts of the stem and the leaves of $\mathrm{Pz}$ by using the agar well diffusion method against six bacterial species and nine fungal species. The result reveals that $\mathrm{Pz}$ leaf extract demonstrated maximum antimicrobial activity against both Staphylococcus aureus and Fusarium oxysporum. The stem extract was found to be more antimicrobial against the Pseudomonas aeruginosa and the Penicillium expansum species ${ }^{63}$. An in vitro research, plumbagin was investigated against methicillin-resistant Staphylococcus aureus (MRSA) for antimicrobial activity. Approximately 100 MRSA isolates which included multidrug-resistant phenotypes displayed consistent behaviour with a narrow minimum inhibitory concentration (MIC) range of 4-8 $\mu \mathrm{g} / \mathrm{ml}$. The time-kill study revealed a 99\% kill of a reference MRSA strain, $8 \mathrm{~h}$ after exposure to plumbagin 64 . A study carried out to investigate the antifungal activity of $\mathrm{Pz}$ against four pathogenic fungal species Fusarium oxysporum, Rhizoctonia solanii, Alternaria sp. and Sclerotium rolfsii. The excellent inhibitory activities were observed against Alternaria spp. (98\%), F. oxysporum (68\%), R. solanii (97.5\%) followed by S. rolfsii $(93.4 \%)$ at $62.5 \mu \mathrm{g} / \mathrm{ml}^{5}$.

\section{CONCLUSION}

Medicinal plants are the primary source of effective herbal medicines for treating various diseases. Herbal products have been used over the past decade because of their numerous pharmacological actions. Pz has been used in Ayurvedic and Unani medicine for centuries to improve longevity and vitality. It is the most significant medicinal plant used widely in herbal formulations. It is chemically rich with its diverse content of active compounds, such as plumbazin, chitranone, zeylanone and many useful naphthaquinone constituents as a multipurpose medicinal agentwere present. $\mathrm{Pz}$ is one of the important medicinal plants which have several pharmacological properties such as anticancer activity, antimicrobial activity, antioxidant activity, anti-inflammatory activity etc. This also given the opportunities to the researchers in this area for potential research and development. This is an effort to collect and record information on Pz's anti-inflammatory and antimicrobial activity and to highlight the needs for research and development.

\section{Acknowledgement}

Authors are thankful to library staff of NIUM for providing all kinds of literature related to this manuscript at the time of writing.

\section{Conflict of interest}

There is no conflict of interest to declare.

\section{REFERENCES}

1. Komakech R, Kim Y, Matsabisa GM, Kang Y. Anti-inflammatory and analgesic potential of Tamarindus indica Linn. (Fabaceae): a narrative review. Integr Med Res. 2019; 8(3):181-6.
2. Li RW, Myers SP, Leach DN, Lin GD, Leach G. A cross-cultural study: Anti-inflammatory activity of Australian and Chinese plants. J Ethnopharmacol. 2003; 85(1):25-32.

3. Balouiri M, Sadiki M, Ibnsouda SK. Methods for in vitro evaluating antimicrobial activity: A review. J Pharm Anal. 2016; 6(2):71-9.

4. Ajayi GO, Oladipo Ademuyiwa, Olagunju JA, Francis A Faduyile. Biochemical and toxicological implications of ethylacetate fraction of the methanolic extract of Plumbago zeylanica (Linn) root. J Phytopharm. 2019; 8(4):192-8.

5. Jain P, Sharma HP, Singh P. Anti-fungal, anti-oxidant and phytochemical analysis of Plumbago zeylanica L. Vegetos. 2020;

6. Dev SK, Choudhury PK, Srivastava R, Sharma M. Phytochemical Characterization and Antioxidant Assessment of Herbal Extracts. J Drug Deliv Ther. 2018; 8(4):126-33.

7. Ravindran A, Gayan J, Das BN. A Standardized Protocol for Genomic DNA Isolation from the Species of Plumbago Linn. Int J Life-Sciences Sci Res. 2017; 3(5):1345-9.

8. Rajakrishnan R, Lekshmi R, Benil PB, Thomas J, AlFarhan AH, Rakesh V, et al. Phytochemical evaluation of roots of Plumbago zeylanica L. and assessment of its potential as a nephroprotective agent. Saudi J Biol Sci. 2017; 24(4):760-6.

9. Tokarz KM, Makowski W, Tokarz B, Hanula M, Sitek E, Muszyńska E, et al. Can ceylon leadwort (Plumbago zeylanica L.) acclimate to lead toxicity? - studies of photosynthetic apparatus efficiency. Int J Mol Sci. 2020; 21(5).

10. Roy A, Bharadvaja N. A review on pharmaceutically important medical plant: Plumbago zeylanica. J Ayurvedic Herb Med [Internet]. 2017; 3(4):225-8. Available from: www.ayurvedjournal.com

11. Xue D, Pan ST, Zhou X, Ye F, Zhou Q, Shi F, et al. Plumbagin Enhances the Anticancer Efficacy of Cisplatin by Increasing Intracellular ROS in Human Tongue Squamous Cell Carcinoma. Oxid Med Cell Longev. 2020; 2020.

12. Khare CP. Indian Medicinal Plants An Illustrated Dictionary. Berlin/Heidelberg: Springer Science+Business Media, LLC; 2007.

13. Ibn Sina I. Al Qanoon Fit Tib. Vol. I-V (Urdu). New Delhi (India): IdaraKitabulShifa; 2007.

14. Akbar S. Handbook of 200 Medicinal Plants [Internet]. Handbook of 200 Medicinal Plants. Cham: Springer International Publishing; 2020. Available from: http://link.springer.com/10.1007/978-3-030-16807-0

15. Dohare B, Jain B, Khare S, Jain K. Comparative Estimation of Plumbagin in Aerial and Root Part of Plumbago zeylanica Using UV-Visible Spectrophotometric. UK J Pharm Biosci. 2015; 3(3): 9 .

16. Austin A, Babu K, Austin A. Macro and Micro-morphological studies on roots of Plumbago indica L . and Plumbago zeylanica L. 2016; 5(5):351-3.

17. Jain P, Sharma HP, Basri F, Baraik B, Kumari S, Pathak C Pharmacological profiles of ethno-medicinal plant: Plumbago zeylanica 1.- A review. Int J Pharm Sci Rev Res. 2014; 24(1):157-63.

18. Roy A, Bharadvaja N. Effect of various culture conditions on shoot multiplication and GC-MS analysis of Plumbago zeylanica accessions for plumbagin production. Acta Physiol Plant. 2018; 40(11):1-10.

19. Chauhan M. A review on Morphology, Phytochemistry and Pharmacological activities of medicinal herb Plumbago Zeylanica Linn. J Pharmacogn Phytochem. 2014; 3(2):95-118.

20. Abhijith APC, Hill DE. Sticky floral stems and jumping spiders ( Araneae : Salticidae ). 2020; 8415(February):1-10.

21. Mandavkar YD, Jalalpure SS. A comprehensive review on Plumbago zeylanica linn. African J Pharm Pharmacol. 2011; 5(25):2738-47.

22. Panda S, Naik D, Kamble A. Population structure and genetic diversity of the perennial medicinal shrub Plumbago. AoB Plants. 2015; 7(1):1-12.

23. Nurtjahja-Tjendraputra E, Ammit AJ, Roufogalis BD, Tran VH, Duke CC. Effective anti-platelet and COX-1 enzyme inhibitors from pungent constituents of ginger. Thromb Res. 2003; 111(4-5):259-65.

24. Mutie FM, Gao LL, Kathambi V, Rono PC, Musili PM, Ngugi G, et al. An Ethnobotanical Survey of a Dryland Botanical Garden and Its Environs in Kenya: The Mutomo Hill Plant Sanctuary. Evidence-based Complement Altern Med. 2020; 2020. 
25. Afolayan FID, Sulaiman KA, Okunade WT. Ethnobotanical survey of plants used in cancer therapy in Iwo and Ibadan, South-Western of Nigeria. J Pharm Pharmacogn Res [Internet]. 2020; 8(5):346-67. Available from:

http://jppres.com/jppreshttp://jppres.com/

26. Cascadden Z, Lyons D, Paris E. On the surface: an ethnoarchaeological study of marginalised pottery production and the social context of pottery surface treatments in Tigray Regional State, northern highland Ethiopia. Azania. 2020; 55(1):69-96.

27. Ferdous T, Hossain MN. Bioresearch Communications Review Article A review on traditional medicinal plants used to treat gynaecological disorder in. 2020; 06(01).

28. Saxena A, Gautam S, Ram Arya K, Kant Singh R. Comparative Study of Phytochemicals, Antioxidative Potential \& Activity of Enzymatic Antioxidants of Eclipta alba and Plumbago zeylanica by in vitro Assays. Free Radicals Antioxidants. 2016; 6(2):139-44.

29. Pant M, Lal A, Rana S, Rani A. Plumbago Zeylanica L.: a Mini Review. Int J Pharm Appl. 2012;

30. Tikadar P, Palita SK, Panda D. Phytochemical profiling of selected medicinal plants used by Paraja tribe of Koraput, India.Copyright@ EM Int. 2020; 26(1):2020-148.

31. Priya Velammal S, Devi TA, Amaladhas TP. Antioxidant, antimicrobial and cytotoxic activities of silver and gold nanoparticles synthesized using Plumbago zeylanica bark. J Nanostructure Chem. 2016; 6(3):247-60.

32. Chaudhari SS, Chaudhari AS. Phytochemical and biological evaluation of roots of Plumbago Linn . 2018; 5(4):274-83.

33. Patwardhan RB, Dhakephalkar PK, Chopade BA, Dhavale DD, Bhonde RR. Purification and characterization of an active principle, lawsone, responsible for the plasmid curing activity of Plumbago zeylanica root extracts. Front Microbiol. 2018; 9(NOV):1-10.

34. Arunachalam KD, Velmurugan P, Raja RB. Anti-inflammatory and cytotoxic effects of extract from Plumbago zeylanica. African J Microbiol Res. 2010; 4(12):1239-45.

35. Oyedapo 00. Studies on bioactivity of the root extract of Plumbago zeylanica. Pharm Biol. 1996;

36. Checker R, Sharma D, Sandur SK, Khanam S, Poduval TB. Antiinflammatory effects of plumbagin are mediated by inhibition of NF-kappaB activation in lymphocytes. Int

Immunopharmacol. 2009; 9(7-8):949-58.

37. Sheeja E, Joshi SB, Jain DC. Bioassay-guided isolation of antiinflammatory and antinociceptive compound from Plumbago zeylanica leaf. Pharm Biol. 2010; 48(4):381-7.

38. Dang GK, Parekar RR, Kamat SK, Scindia AM, Rege NN. Antiinflammatory activity of Phyllanthus emblica, Plumbago zeylanica and Cyperus rotundus in acute models of inflammation. Phyther Res. 2011; 25(6):904-8.

39. V. T, Kaliyamurthi Venkatachalam L V., Natarajan S, Pitchiah Kumar Murugan JAS. Hydroalcoholic Extract of Plumbago Zeylanica Linn root bark exhibit Analgesic and AntiInflammatory activities in Experimental Rat models. Am J Pharm Heal Res. 2014;

40. Nile SH, Patil UB, Park SW. HPTLC analysis, antioxidant, antiinflammatory and xanthine oxidase inhibitory activity of Plumbago zeylanica L. Chiang Mai J Sci. 2015;42(4):886-95.

41. Shaikh RU, Pund MM, Gacche RN. Evaluation of antiinflammatory activity of selected medicinal plants used in Indian traditional medication system in vitro as well as in vivo. J Tradit Complement Med. 2016; 6(4):355-61.

42. Aparanji P. EFFECT OF PLUMBAGO ZEYLANICA ETHYL ACETATE EXTRACT IN PREVENTION OR TREATMENT OF ARTHRITIS USING ADJUVANT INDUCED ARTHRITIC RAT MODEL. Indian J Appl Res. 2018;7.

43. Subramaniyan V, Paramasivam V. Potential anti-inflammatory activity of Plumbago zeylanica. Asian J Pharm Clin Res. 2017; 10(10):372-5.

44. Zaki AM, El-Tanbouly DM, Abdelsalam RM, Zaki HF. Plumbagin ameliorates hepatic ischemia-reperfusion injury in rats: Role of high mobility group box 1 in inflammation, oxidative stress and apoptosis. Biomed Pharmacother. 2018; 106(May):78593.

45. Abdul KM, Ramchender RP. Modulatory effect of plumbagin (5-hydroxy-2-methyl-1,4-naphthoquinone) on macrophage functions in BALB/c mice. I. Potentiation of macrophage bactericidal activity. Immunopharmacology. 1995; 30(3):2316.

46. Ahmad I, Aqil F. In vitro efficacy of bioactive extracts of 15 medicinal plants against ES $\beta$ L-producing multidrug-resistant enteric bacteria. Microbiol Res. 2007; 162(3):264-75.

47. Lemma H, Debella A, Addis G, Kunert O, Geyid A, Teka F, et al. Anti-bacterial activity of Plumbago zeylanica L. roots on some pneumonia causing pathogens. SINET Ethiop J Sci. 2002;

48. Mossa JS, El-Feraly FS, Muhammad I. Antimycobacterial constituents from Juniperus procera, Ferula communis and Plumbago zeylanica and their in vitro synergistic activity with isonicotinic acid hydrazide. Phyther Res. 2004; 18(11):934-7.

49. Wang YC, Huang TL. Anti-Helicobacter pylori activity of Plumbago zeylanica L. FEMS Immunol Med Microbiol. 2005; 43(3):407-12.

50. Aqil F, Ahmad I, Owais M. Evaluation of anti-methicillinresistant Staphylococcus aureus (MRSA) activity and synergy of some bioactive plant extracts. Biotechnol J. 2006; 1(10):1093-102.

51. Aqil F, Ahmad I. Antibacterial properties of traditionally used Indian medicinal plants. Methods Find Exp Clin Pharmacol. 2007; 29(2):79-92.

52. Jeyachandran R, Mahesh A, Cindrella L, Sudhakar S, Pazhanichamy K. Antibacterial activity of plumbagin and root extracts of Plumbago Zeylanica L. Acta Biol Cracoviensia Ser Bot. 2009;

53. Mallikadevi T, Paulsamy S. "Plumbago zeylanica L.-a potential plant for antimicrobial activity. Plant Arch. 2010; 10(2):54750

54. Jetty A, Subhakar C, Rajagopal D, Jetty M, Subramanyam M, Marthanda Murthy M. Antimicrobial activities of neo- and 1epineo-isoshinanolones from Plumbago zeylanica roots. Pharm Biol. 2010; 48(9):1007-11.

55. Kataki MS, Sharma DN, Kumar S, Yadav RS, Rajkumari A. Antibacterial activity, in vitro antioxidant activity and anthelmintic activity of methanolic extract of Plumbago zeylanica L . leaves. J Pharm Res. 2010; 3(12):2908-12.

56. Dhale DA, Markandeya SK. Antimicrobial and Phytochemical Screening of Plumbago zeylanica Linn. (Plumbaginaceae) Leaf. J Exp Sci [Internet]. 2011; 2(3):04-6. Available from: file:///C:/Users/Usuario/Downloads/Exp Sci 6028-16279-1PB[1] (Dhale).pdf

57. Ravikumar VR, Sudha T. Phytochemical and antimicrobial studies on Plumbago zeylanica (L)(Plumbaginaceae). Int J Res Pharm Chem. 2011; 1(2):185-8.

58. Banik B, Sarkar P, Sultana F, Saikia M, Dey A. In-vitro antimicrobial screening with phytochemical study of Plumbago zeylanica L. collected from two regions of Eastern Himalayas- A comparative study. Int J Phytopharm. 2014;

59. Patwardhan RB, Dhakephalkar PK, Chopade BA. Antibacterial and plasmid curing activities of root extracts of. Int J Herbo Medica. 2015; 2(1):13-25.

60. Shweta S, Dubey S. Antimicrobial Activity of Leaves Extract of Plumbago Zeylanica Plant against Known Drugs\&quot; Int J Res Stud Biosci [Internet]. 2015;3(6):1-6. Available from: www.arcjournals.org

61. Abera A, Mekonnen A, Tebeka T. Studies on antioxidant and antimicrobial activities of Plumbago zeylanica Linn. Traditionally used for the treatments of intestinal warms and skin diseases in Ethiopia. Res J Med Plant. 2015; 9(6):252-63.

62. Karthika KSM. Antibacterial activity of plant extract Plumbago zeylanica against clinical bacteria. Int J Sci Environ Technol. 2015; 4(6):1603-7.

63. Singh MK, Pandey A, Sawarkar H, Gupta A, Gidwani B, Dhongade H, et al. Methanolic extract of Plumbago zeylanica A remarkable antibacterial agent against many human and agricultural pathogens. J Pharmacopuncture. 2017; 20(1):1822.

64. Periasamy H, Iswarya S, Pavithra N, Senthilnathan S, Gnanamani A. In vitro antibacterial activity of plumbagin isolated from Plumbago zeylanica L. against methicillinresistant Staphylococcus aureus. Lett Appl Microbiol. 2019; 69(1):41-9. 